\title{
BEYOND BUDGETING - PERCEPÇÕES E ADAPTABILIDADE AO VAREJO BANCÁRIO: PESQUISA JUNTO AOS GESTORES DE UM GRANDE BANCO BRASILEIRO
}

\section{BEYOND BUDGETING - PERCEPTIONS AND ADAPTATIONS TO RETAIL BANKS: RESEARCH WITH MANAGERS OF A BRAZILIAN BANK}

\author{
Ivam Ricardo Peleias ${ }^{2}$ \\ José Elias Neto ${ }^{3}$ \\ João Bosco Segreti ${ }^{4}$ \\ Aldy Fernandes da Silva ${ }^{5}$
}

\begin{abstract}
RESUMO: Este trabalho procurou identificar e analisar as percepções de um grupo de gestores de um grande banco brasileiro de varejo, sobre o processo orçamentário e os comportamentos a ele vinculados, relativos ao Beyond Budgeting, para estudar sua aplicabilidade à organização. Buscou-se detectar as percepções dos gestores sobre a existência de falhas no uso do orçamento na forma tradicional e evidências de comportamentos indesejados. A revisão da literatura revelou que o Beyond Budget, pouco estudado no Brasil, apresenta-se como um modelo de gestão sem orçamentos, e que seria mais eficiente e adaptado ao atual momento de evolução das empresas. É uma pesquisa descritiva e exploratória, do tipo survey, na qual usou-se para o trabalho de campo um questionário com duas partes, aplicado a um grupo de gestores do banco. A primeira parte do questionário buscou identificar o perfil dos respondentes; a segunda, com 18 assertivas pretendeu identificar as percepções. Os dados foram analisados com o auxílio da Estatística Descritiva e das técnicas de Análise de Clusters, Fatorial e de Correspondência. Foram identificados dois clusters, categorizando os respondentes e suas respectivas visões sobre o processo orçamentário e o uso do Beyond Budgeting, em relação aos cinco fatores obtidos. Dos resultados obtidos, destacou-se a percepção dos respondentes sobre falhas no atual sistema orçamentário, o que poderia indicar a necessidade de se adotar um novo modelo.
\end{abstract}

PALAVRAS-CHAVE: Orçamento, Bancos, Sistemas de controle gerencial.

ABSTRACT: The aim of this research was to identify and analyze the perceptions of a group of managers from an important retail bank about the budget process and its behaviors - related to Beyond Budget - as a means to study its applicability inside that company. It was detected the managers perceptions on possible flaws when using the budget in its traditional way as well as undesirable behaviors. It was shown that the Beyond Budget such a theme is not explored a lot in Brazil, and it presents itself as a managing model without budgets. Moreover, this model would be much more efficient in developing companies nowadays. This research was a descriptive and exploratory survey, and it was applied a questionnaire divided into two parts to a group of managers from the studied bank. The objective of the first part was to identify the subjects profiles, and the second, composed of 18 assertives, to identify their perceptions. The data were analyzed through the use of Descriptive Analysis, Cluster Analysis and Factorial Analysis. It was identified two clusters as well as their points of view on the budget process and the use of Beyond Budgeting concerning the five obtained factors. From those results, it stands out the subjects perceptions on flaws in the current budget system. This could show that it is necessary to adopt a new model.

KEY-WORDS: Budget, Banks, management control systems.

\footnotetext{
${ }^{1}$ Artigo Recebido em 15.10.2009. Revisado por pares em 09.08.2011. Recomendado em 09.08.2011 por Edson Roberto Scharf - Editor Responsável. Publicado em 13.06.2012.

Organização Responsável pelo periódico: Universidade Regional de Blumenau - FURB - www.furb.br/rn
}

\footnotetext{
${ }^{2}$ Centro Universitário - FECAP - ivamrp@fecap.br

${ }^{3}$ Centro Universitário - FECAP - eliasneto@oi.com.br

${ }^{4}$ Centro Universitário - FECAP - $\underline{\text { segreti@uol.com.br }}$

5 Centro Universitário - FECAP - $\underline{\text { aldy@ fecap.br }}$
} 


\section{BEYOND BUDGETING - PERCEPÇÕES E ADAPTABILIDADE AO VAREJO BANCÁRIO: PESQUISA JUNTO AOS GESTORES DE UM GRANDE BANCO BRASILEIRO}

\section{INTRODUÇÃO}

Muitas empresas usam orçamentos para projetar, em termos físicos e financeiros, as expectativas para períodos futuros, para garantir que o planejamento estratégico seja seguido. O orçamento é uma ferramenta de gestão usada para quantificar, controlar e acompanhar as metas estabelecidas pela cúpula da empresa e, serve de parâmetro para avaliar o desempenho dos gestores, das áreas de responsabilidade e do resultado dos produtos e serviços (PELEIAS, 2002, P. 26-27). Os orçamentos podem ser usados em conjunto com outras ferramentas, tais como o Balanced Scorecard. (SHASTRI, STOUT, 2008, p. 24), da mesma forma que o banco objeto desta pesquisa.

Zdanowicz (apud Lunkes, 2003) mencionou que o orçamento como é conhecido atualmente surgiu no setor público, sendo usado pela primeira vez por empresa privada na $\mathrm{Du}$ Pont de Memours (EUA), em 1919. Lunkes (2003) apresentou a evolução do processo orçamentário desde sua criação, em seis etapas: Empresarial, Contínuo, de Base Zero, Flexível, por Atividades e Perpétuo. Apesar da evolução identificada, alguns autores apontam que os modelos orçamentários apresentam deficiências e, não raramente são criticados.

Em um processo evolutivo na concepção, teste e uso das ferramentas de gestão, uma nova opção se apresentou: o Beyond Budgeting, cuja tradução literal seria "além do orçamento". Seu surgimento ocorreu no final dos anos 1990, ocasião em que se levantou a discussão sobre os custos com o processo orçamentário, os quais, conjugados com outros fatores comportamentais, levaram ao questionamento de sua necessidade. Essa discussão fomentou a criação de uma idéia que evoluiu, segundo seus defensores, para uma comunidade, (BBRT, 2006). Essa comunidade considera o que eles denominaram de "formas tradicionais de orçamento e de sistemas de avaliação de desempenho" como responsáveis (ao menos parcialmente) por desvios de comportamento, dificuldades na correta alocação de recursos e tomada de decisões míopes.

O modelo é divulgado e defendido pelo BBRT - Beyond Budgeting Roundtable, grupo criado para discutir e avaliar sua aplicação (BBRT, 2006); entretanto, ainda é pouco usado. A observação da realidade revelou que o setor financeiro, cenário desta pesquisa, usa sistemas apoiados por orçamentos fixos, com vinculação direta da remuneração variável dos executivos e colaboradores ao alcance das metas orçamentárias estabelecidas.

Este panorama poderá se alterar, pois até 2010 todas as instituições financeiras deverão adaptar seus sistemas contábeis para se adequar aos padrões internacionais, por determinação do Banco Central do Brasil (BACEN, 2006). Algumas ações, dentre as quais o maior controle interno principalmente por conta dos Acordos de Basiléia, a maior competição pela clientela, a redução das taxas básicas de juros e as previsões de ajustes ainda mais fortes nos próximos períodos, podem levar a uma forte diminuição nos lucros, principalmente pelo seu impacto direto nos spreads.

Em função dessas mudanças e desafios, poderá ser preciso modificar e / ou substituir os atuais sistemas de gestão, para se manter a competitividade dos bancos brasileiros. Uma alternativa seria adotar um modelo sem orçamento. Assim, identificou-se a oportunidade de pesquisar se há indícios de "malefícios" no processo orçamentário do banco em estudo, que 
indiquem se o Beyond Budgeting traria maiores dinamismo e competitividade, contribuindo para a obtenção de resultados futuros favoráveis.

Max (2005) apontou que muitas empresas do setor financeiro norte-americano vêm adotando as linhas do Beyond Budgeting nos últimos anos. Dentre os motivos que as levaram a mudar seu sistema de gestão, o autor (2005) destacou: o desejo de melhorar a precisão nas estimativas; a necessidade de direcionar o foco para negócios de alta performance; a necessidade de incrementar a agilidade e conformidade dos negócios às condições de competição do mercado.

Outros trabalhos internacionais vêm debatendo e estudando os efeitos da adoção do Beyond Budgeting (DAUM et al, 2005; WALL, 2005; LINDSAY, LIBBY, 2007). Em síntese, todos reconhecem que o processo orçamentário em sua forma tradicional precisa de melhorias e que uma alternativa seria a adoção do Beyond Budgeting.

No Brasil, Frezatti (2004) realizou análise comparativa sobre os questionamentos do BBRT em relação ao orçamento tradicional e concluiu que alguns problemas não seriam resolvidos pelo novo modelo, além da possibilidade da criação de outros. Barbosa Filho e Parisi (2004) constataram a ausência comprovação empírica do modelo em nosso País e realizaram uma investigação junto a executivos da Sadia S/A., usando o instrumento de pesquisa adotado pelo Beyond Budgeting Round Table (BBRT). Constataram uma tendência para a adoção dos princípios do Beyond Budgeting e admitiram que seus princípios seriam avançados e capazes de gerar conhecimento nas empresas. Os dois trabalhos nacionais reconhecem que o processo orçamentário tradicional pode ser melhorado com a adoção do Beyond Budgeting.

O quanto constatado no Brasil e no exterior despertou o interesse e revelou a oportunidade para a realização desta pesquisa, cujo objetivo geral foi identificar e estudar as percepções dos gestores de um grande banco brasileiro de varejo, a respeito de problemas causados pelo processo orçamentário, que justificassem sua substituição pelo modelo Beyond Budgeting. O problema formulado foi: "Existem evidências suficientes que justifiquem a substituição do atual modelo de gestão, baseado em orçamentos fixos, pelo Beyond Budgeting na instituição financeira estudada?"

\section{REFERENCIAL TEÓRICO}

\subsection{Orçamento: Conceitos, Princípios e Características}

$\mathrm{Na}$ linguagem comum, Koogan e Houaiss (1998) descreveram orçamento como "cálculo da receita e da despesa / Descrição pormenorizada dos materiais e das operações necessárias para realizar uma obra com a estimativa da despesa (...)". Na consulta ao léxico, depreende-se que orçar é sinônimo de calcular, avaliar, fazer estimativa. Na atividade empresarial, o termo está ligado à previsão ou projeção de receitas, custos, despesas e outros elementos que afetam o patrimônio e os resultados das organizações.

Rachlin (1999) asseverou que o orçamento é a expressão formal dos planos e objetivos de gestão, para todas as fases operacionais em um período de tempo. Brookson (2000) e Horngren, Foster e Datar (1997) apontaram como características dos orçamentos: 


\section{BEYOND BUDGETING - PERCEPÇÕES E ADAPTABILIDADE AO VAREJO BANCÁRIO: PESQUISA JUNTO AOS GESTORES DE UM GRANDE BANCO BRASILEIRO}

detalhamento de atividades futuras em um plano; quantificação das expectativas; materialização em valores dos projetos e planos; abordagem de aspectos financeiros e não financeiros.

O orçamento permite alcançar seis objetivos principais (BROOKSON, 2000, p. 9): planejamento, auxiliando a programar atividades de forma lógica e sistemática, em consonância com a estratégia de longo prazo da empresa; coordenação, ajudando a coordenar as atividades das várias partes da empresa, garantindo a consistência dessas ações; comunicação, ajudando a informar mais facilmente os objetivos, oportunidades e planos aos vários gestores; motivação, como estímulo aos gestores para atingirem metas pessoais e da empresa; controle, por permitir comparar as atividades realizadas com os planos originais, fazendo ajustes onde for necessário; avaliação, ao fornecer as bases para a avaliação de cada gestor, tendo em vista suas metas pessoais e as da área sob sua responsabilidade.

Welsch (1983, p.21) substituiu a expressão "planejamento e controle dos resultados" por orçamentos globais ou controle orçamentário, definindo-os como "um enfoque sistemático e formal à execução das responsabilidades de planejamento, coordenação e controle da administração".

Verifica-se, nas obras citadas, que é possível elaborar o orçamento empresarial adotando-se a seqüência: vendas, compras, produção, investimento, despesas de comercialização e administração, caixa, capital e outros. Após a confecção integrada das várias peças, a elaboração orçamentária se encerraria com as demonstrações contábeis projetadas.

Elaborar e usar os orçamentos no processo de gestão são práticas adotadas por organizações, com benefícios apontados na literatura; mas há controvérsias. Para Brookson (2000, p.19) os orçamentos aumentam a papelada e podem drenar muita força de trabalho, sobretudo em estágios iniciais; seus resultados emergem lentamente, e seus benefícios somente seriam vistos no ano seguinte; seu uso requer padronização, o que levaria à falta de flexibilidade; pode haver resistência de gerentes relutantes em adotar novos procedimentos.

Lunkes (2003) apontou uma lista de fatores que podem levar os orçamentos a falhar: estrutura organizacional inadequada; sistema de custeio inadequado; falta de apoio da cúpula da empresa; ausência de flexibilidade suficiente para reformular as estimativas; técnica rudimentar de revisão; papelada com muitos detalhes; uso excessivo de séries históricas para estabelecer objetivos; aplicação de cortes gerais nos custos, sem analisar detalhes de cada área; análise tardia dos resultados, não corrigindo de imediato eventual anomalia; excessiva associação dos custos na preparação do orçamento; incapacidade de adaptar-se ao ambiente em constantes mudanças e à conseqüiente modificação das metas.

Apesar das falhas apontadas, e das mencionadas desvantagens e limitações, Brookson (2000) indicou que os sistemas de avaliação de desempenho (e conseqüentemente o de recompensas) devem ser baseados no orçamento.

Algumas das críticas mais contundentes ao orçamento, apontadas por defensores do Beyond Budgeting são: sistemas de recompensa baseados em orçamentos premiam as pessoas 
por mentir e as punem por dizerem a verdade (JENSEN, 2000, p.2), e que não haveria como aperfeiçoar o orçamento, um mal que prejudica as instituições, trazendo custos e provocando análises e comportamentos inadequados (JENSEN, 2001; HOPE, FRASER, 2003).

\subsection{Beyond Budgeting - Histórico e Princípios}

Após a leitura das proposições de seus defensores, pode-se dizer que o Beyond Budgeting é uma metodologia de gestão flexível, descentralizada e participativa que abomina os orçamentos como base para a gestão e controle de resultados. Segundo os defensores do Beyond Budgeting, o uso generalizado dos orçamentos seria uma prática comum entre o que eles denominaram de "sistemas de gestão tradicionais".

Hope e Fraser (2003) propugnaram que os processos orçamentários adotados hoje por muitas empresas devem ser abolidos. Apesar de parecer uma proposta radical, para os autores a mudança seria necessária, para que organizações de hierarquia centralizada se convertessem em redes descentralizadas, que conseguissem adaptação mais rápida às condições de mercado. Os autores acreditam que a tecnologia, usada de forma conjugada com um amplo leque de ferramentas gerenciais, permitiria uma gestão moderna e eficaz e que a maioria das empresas fica premida pelo orçamento, pois a cultura de comando e controle impede que conceitos de descentralização e empowerment prevaleçam.

Os autores (2003) informaram que as empresas consomem 25.000 dias-homem a cada US\$ 1 bilhão de faturamento anual com orçamentos. Jensen (2001) afirmou que as empresas gastam fortunas com planejamento orçamentário e discussões inócuas, além do que o processo incentiva os executivos a mentirem quanto à verdadeira capacidade da equipe, buscando orçamentos "favoráveis" que facilitem a conquista de bônus, ao invés de incentivarem a conquista do mercado e vencer os concorrentes.

Para seus defensores, o fim do orçamento é uma parte do modelo. O Beyond Budgeting seria uma alternativa ao modelo "taylorista" de comando e controle de gestão. Mais que planejar e avaliar o desempenho, seria uma forma diferente de gerenciar e liderar organizações. Os princípios que apóiam a definição de metas, os sistemas de recompensa, planejamento e estratégia, além das políticas de aporte de recursos, coordenação e controle seriam distintos dos usados pelas empresas por eles denominadas de "tradicionais". Para seus defensores, identificados no item 2.3, este novo modelo incentiva a autodefinição de metas, recompensas para as equipes e não por desempenho individual, descentralização, coordenação e controle mais dinâmicos e direcionados a soluções.

\subsection{Estrutura do Modelo Beyond Budgeting}

Para Hope e Fraser (2003; 2006;) e Pflaeging (2005) o modelo Beyond Budgeting focaliza um grupo de Fatores de Sucesso Competitivo (Competitive Success Factors- CSF) com doze princípios que constituem suas estruturas de sustentação: framework de adaptação e framework de devolução.

Os CSF considerados são: respostas rápidas - para responder rapidamente aos imprevistos; inovação - para acompanhar as mudanças das necessidades do cliente; excelência operacional - para obter baixos custos, alta qualidade e produtos e serviços 


\section{BEYOND BUDGETING - PERCEPÇÕES E ADAPTABILIDADE AO VAREJO BANCÁRIO: PESQUISA JUNTO AOS GESTORES DE UM GRANDE BANCO BRASILEIRO}

rentáveis; intimidade com o cliente - para construir relacionamentos de longo prazo com os clientes; melhores equipes - para atrair e conservar os melhores talentos; comportamento ético - busca de altos padrões éticos; performance financeira - para sustentar desempenho financeiro superior.

O framework de adaptação agrupa os princípios de gestão de desempenho. O Beyond Budgeting é baseado em conceitos de melhoria contínua e análises comparativas, ao invés de contratos fixos de desempenho normalmente usados, situações nas quais se confronta o resultado obtido com o orçado. São seis princípios: metas baseadas na maximização do desempenho potencial; avaliações e recompensas baseadas em contratos de melhoria relativa, considerando-se a natureza ou razões dos fatores impactantes; fazer dos planos de ação um processo contínuo e inclusivo; tornar os recursos disponíveis sempre que solicitados; coordenar as ações na empresa para que prevaleçam as demandas do cliente; controles baseados em governança efetiva e num grupo de indicadores de desempenho relativo.

O framework de devolução agrupa princípios de gestão descentralizada, com delegação de autoridade para decisões em níveis operacionais. Essa devolução de responsabilidade habilitaria e encorajaria decisões locais sem pressões, direcionamentos ou constrangimentos. São seis princípios: prover uma estrutura de governança com princípios e limites claros; criar um clima de alto desempenho baseado em sucesso relativo; dar às pessoas liberdade de tomar decisões localmente, consistentes com princípios de governança e metas organizacionais; atribuir a responsabilidade pelas decisões de criação de valor às equipes da "linha de frente"; fazer as pessoas responsáveis pelos resultados obtidos com o cliente; apoiar sistemas de informação éticos e abertos que permitam "verdade única" na organização.

Ao defenderem o modelo, Hope e Fraser (2003) procuraram demonstrar como o Beyond Budgeting poderia apoiar os fatores de sucesso na "economia da informação". Para os autores, a liderança baseada em princípios do Beyond Budgeting permitiria usufruir todo o potencial das ferramentas oferecidas. Isso tornaria seus processos adaptativos, o que permitiria formar equipes comprometidas, capazes e com poder de decisão delegado, que cheguem a estratégias inovadoras, baixos custos, clientes fiéis e com ética, garantindo o sucesso competitivo.

O Beyond Budgeting vem sendo usado por empresas: Borealis, American Express, Dell Tecnologia, Toyota, Svenska Handelsbanken e outros. No Brasil, algumas empresas já estariam trabalhando "sem orçamentos", tais como: Rhodia, Philips e Ericsson. Outras estariam tentando "extinguir" os orçamentos, tais como Datasul e Votorantim Celulose e Papel - VCP (BBRT, 2006).

\section{METODOLOGIA DE PESQUISA}

\subsection{Tipificação}

A pesquisa é descritiva, do tipo survey (COLLINS, HUSSEY, 2005, p. 70), pois buscou identificar e analisar as percepções de um grupo de gestores de um grande banco brasileiro de varejo, sobre o processo orçamentário e os comportamentos a ele vinculados, relativos ao Beyond Budgeting, estudando sua aplicabilidade à instituição. Verificou-se que a 
questão de pesquisa poderia ser respondida por um trabalho de campo, ainda que as variáveis não fossem de controle dos pesquisadores (LEE, 1999, p. 54).

A pesquisa é também exploratória, pois buscou aprimorar idéias ou descobrir intuições, usando de forma combinada, técnicas qualitativas e quantitativas (COOPER, SCHINDLER, 2003). A Administração do banco permitiu a realização da pesquisa e a consulta a documentos internos sobre o processo de gestão. Na visão de Malhora (2001), a pesquisa exploratória inclui dados primários, gerados pelo pesquisador para solucionar o problema, e secundários, coletados anteriormente para objetivos diferentes do estudo. Os dados primários foram obtidos com a aplicação de um questionário, e os secundários foram coletados de normativos, publicações e sites da Internet, dentre outros.

\subsection{O questionário (instrumento) para a coleta dos dados}

Os dados primários foram obtidos com a aplicação de um questionário desenvolvido com base no referencial teórico da pesquisa. Na escolha do tamanho mínimo da amostra, empregou-se o critério empírico aplicado a levantamentos amostrais, com escalas de Likert, de considerar que o número de sujeitos seja no mínimo cinco vezes o número de questões (HAIR JR et al, 2008).

Para atender o problema de pesquisa, o questionário foi estruturado em três partes distintas: a $1^{\mathrm{a}}$ de apresentação, a $2^{\mathrm{a}}$ de qualificação (contendo dados pessoais e corporativos) e a $3^{\mathrm{a}}$ com as assertivas a serem respondidas numa escala de Likert. A apresentação ofereceu orientações gerais, ressaltando que o objetivo da pesquisa era a percepção dos entrevistados sobre os fatos e não o seu comportamento. A $2^{\mathrm{a}}$ parte destinava-se à qualificação dos entrevistados, buscando identificar um grupo de características que poderiam interferir no entendimento e respostas às questões. A $3^{\mathrm{a}}$ parte do questionário conteve as questões relacionadas às percepções dos executivos do banco em relação aos aspectos e influências do orçamento.

O questionário foi aplicado a gestores de agências e a outros funcionários que trabalhavam diariamente com orçamentos. Ficou hospedado em um sítio próprio na Internet por três semanas, obtendo-se 93 respostas de uma população de 362 colaboradores da empresa. A decisão de aplicar os questionários aos gestores acolheu a recomendação feita por Shastri e Stout (2005, p. 25), de avaliar as percepções de pessoas envolvidas na gestão do banco, por eles denominados "usuários" dos orçamentos.

\subsection{Análise Multivariada}

Para identificar e analisar as percepções dos gestores sobre os problemas causados pelo processo orçamentário no banco (assertivas) foram usadas técnicas estatísticas multivariadas: Análise Fatorial, Análise de Correspondência e Análise de Cluster. O uso das Análises Fatorial e de Cluster com escalas do tipo Likert é um procedimento comum na literatura. Pereira (2001, p. 65 e 80) argumenta que apesar deste tipo de escala ter se tornado um paradigma da mensuração qualitativa (escala ordinal), pode-se examinar a adequação de assumir que os intervalos entre as suas categorias sejam regulares, assim como também o estabelecimento de uma categoria que possa corresponder a um zero absoluto (fixação de 


\section{BEYOND BUDGETING - PERCEPÇÕES E ADAPTABILIDADE AO VAREJO BANCÁRIO: PESQUISA JUNTO AOS GESTORES DE UM GRANDE BANCO BRASILEIRO}

premissa de uma escala de razão). Apesar de discussões na literatura sobre sua classificação (Oliveira, 2001; Silva e Simon, 2005), se ordinal ou intervalar/razão, há autores que a usam como uma escala métrica do tipo intervalar ou de razão (HAIR JR. et al, 2008; MALHOTRA, 2001). Silva e Simon (2005) argumentam que a validação de uma escala (mostrar que ela consegue inferir ou medir o que se propõe) pode ser por métodos estatísticos multivariados: Análise Fatorial Exploratória e Confirmatória. Desta forma, as técnicas estatísticas multivariadas de Análise Fatorial e Cluster foram usadas para analisar as percepções dos gestores sobre o processo orçamentário (assertivas).

A Análise Fatorial (Hair Jr. et. al, 2008; Pereira, 2001; Malhotra, 2001) permitiu obter os fatores (dimensões abstratas) que, em geral, podem ser nomeados e interpretados, segundo a composição dada pelas variáveis do questionário (assertivas). A análise fatorial foi usada para agrupar em fatores as percepções dos respondentes quanto ao processo orçamentário do banco.

A Análise de Correspondência foi usada para associar a percepção dos gestores (discordância/concordância) quanto ao processo orçamentário do banco. Esta técnica foi usada, pois é uma ferramenta útil para analisar as percepções de indivíduos medidas numa escala nominal ou ordinal, assim como a escala de Likert. Segundo Pereira (2001), uma vantagem do uso da Análise de Correspondência é permitir a explicação das relações existentes entre as variáveis e suas categorias de resposta em grandes tabelas de contingência, como a obtida de um conjunto de assertivas usando uma escala de Likert.

Finalmente, sempre com o intuito de conhecer a percepção dos gestores quanto ao processo orçamentário do banco, buscou-se associá-las aos perfis de grupos de gestores respondentes. Para tanto, foi usada a Análise de Cluster (ou de agrupamentos), conforme proposto por Hair Jr. et. al (2008) e Pereira (2001).

O uso combinado das técnicas de Análise Fatorial, Análise de Correspondência e Análise de Cluster foi usado na premissa de que a fraqueza de um único método será compensada pela força de outro. O principal objetivo no uso combinado das técnicas estatísticas foi aumentar o grau de confiabilidade da pesquisa, da mesma forma que Fleury, Shinyashiki e Stevanato (1997).

\section{APRESENTAÇÃO E DISCUSSÃO DOS RESULTADOS}

\subsection{Orçamento e Gestão}

O Banco objeto da pesquisa é conhecido por buscar e aplicar inovações em seu processo de gestão. Em 1998, adotou o Balanced Scorecard ${ }^{6}$ como modelo de gestão e o vem usando ao longo do tempo, situação análoga à relatada por Sahstri e Stout (2006, p. 24). O conjunto de indicadores construído considerou quatro etapas: a) elaboração do planejamento estratégico (para 5 anos); b) anualmente, são elaborados o plano diretor e o plano Segmento de Mercados, que traduzem os objetivos determinados pelo Conselho de Administração em

\footnotetext{
${ }^{6}$ A menção ao Balanced Scorecard é feita para elucidar o contexto de gestão do banco objeto da pesquisa. Pesquisas futuras, recomendadas nas considerações finais, poderão ser feitas par aquilatar os efeitos da adoção do Balanced Scorecard na gestão do banco.
} 
metas operacionais; c) as metas são passadas para as vice-presidências, que as distribuem às diretorias, até o nível de agência, na forma de "valores orçados"; d) as áreas definem o conjunto de indicadores que irão compor o BSC.

No processo orçamentário, vem-se buscando a participação das áreas operacionais, com pequenas mudanças no método a cada ano. De forma geral, a partir de certo retorno esperado pelos acionistas e dos direcionamentos estratégicos, projetam-se valores necessários a cada tipo de negócio, que são negociados entre as diretorias e redistribuídos às regiões e às agências. O Balanced Scorecard é construído a partir do orçamento e serve de base para remuneração variável e reconhecimento de desempenho. Todos os indicadores são definidos do nível de diretoria para cima.

Em 2006, foram estabelecidos no Plano Diretor 19 objetivos em 5 dimensões: financeira, clientes, processos internos, sociedade e comportamento organizacional, com 60 indicadores para visualização do Banco, em nível de Conselho Diretor. Para a rede de agências, 30 indicadores direta ou indiretamente ligados aos negócios. $O$ orçamento desdobrado em metas fixas, base dos indicadores, é determinante das avaliações e remuneração variável. Os resultados da pesquisa demonstraram a percepção dos gestores sobre o processo orçamentário e os comportamentos a ele vinculados.

\subsection{Análise Estatística Multivariada}

Por meio da Análise Fatorial e de acordo as escalas de discordância e concordância, foram identificados os fatores mais representativos, e por meio destes, as assertivas que a eles estão associadas. Os testes de adequação, conforme Hair Jr. et al (2008) e Pereira (2001), $(\mathrm{KMO}=0,885$ e Esferecidade de Bartlett: Valor-p = 0,000) foram altamente significantes, indicando que os dados são adequados ao uso da Análise Fatorial.

Realizou-se o teste de Kolmogorov-Smirnov (KS), para avaliar a aderência dos dados obtidos à distribuição normal, que revelou significância menor que 0,05 para as 18 assertivas da escala de Likert, indicando que nenhuma das variáveis analisadas poderia ser considerada normal. A normalidade não é um pressuposto para a análise fatorial, mas as possibilidades de interpretação crescem caso a distribuição seja normal (HARMAN, 1976).

Para escolher o número de fatores, optou-se pelo critério de Normalização de Kaiser, pois os fatores resultantes deveriam ter autovalores maiores que 1. Os dados foram analisados em uma perspectiva quantitativa, pelo método de análise fatorial "alpha factoring", combinado com o método de rotação VARIMAX, obtendo-se uma matriz rotacionada com normalização de Kaiser, por meio do software SPSS ${ }^{\circledR}$ (Statistical Packet for Social Sciences) (SPSS 1999).

Além dos testes de KS, KMO e Esferecidade de Bartlet, testou-se a confiabilidade ou consistência interna dos dados, para verificar a existência ou não de vieses significativos. A consistência interna foi avaliada pelo Alpha de Cronbach. Valores próximos de 1 indicam boa consistência interna, e valores maiores que 0,6 são aceitáveis em pesquisas exploratórias (PASQUALI, 2003). Obteve-se o valor de 0,791 para a escala, indicando boa consistência interna. Os valores do Alpha de Cronbach para os 5 fatores identificados estão na tabela 2. Não foi possível calcular a confiabilidade do quinto fator, composto de apenas uma assertiva. 


\section{BEYOND BUDGETING - PERCEPÇÕES E ADAPTABILIDADE AO VAREJO BANCÁRIO: PESQUISA JUNTO AOS GESTORES DE UM GRANDE BANCO BRASILEIRO}

Entretanto, optou-se por sua apresentação, o que para os pesquisadores contribuiu na melhor apresentação e discussão dos resultados.

A Análise Fatorial permitiu extrair 5 fatores que conjuntamente explicaram 57,8\% da variância total das variáveis (assertivas do questionário). Considerando que a carga fatorial (adotadas cargas maiores ou iguais a 0,40) é a correlação entre a variável e o fator e quanto mais alta a carga fatorial mais a variável é representativa do fator, foram usados esses 5 fatores e identificadas as assertivas do processo de orçamento da instituição à eles associados. Os resultados estão apresentados na Tabela 1.

Tabela 1 - Fatores extraídos e variância explicada.

\begin{tabular}{c|c|c|c|c}
\hline Fatores & \multirow{2}{*}{ Auto-valores } & \multicolumn{2}{|c|}{$\%$ da variância } & Denominação do fator \\
\cline { 3 - 4 } & & Do fator & Cumulativa & \\
\hline $\mathbf{1}$ & 4,187 & 23,261 & 23,261 & Eficiência na correção de erros \\
$\mathbf{2}$ & 2,105 & 11,693 & 34,954 & Cumprimento de metas \\
$\mathbf{3}$ & 1,602 & 8,902 & 43,855 & Burocracia \\
$\mathbf{4}$ & 1,338 & 7,432 & 51,288 & Hierarquia na tomada de decisões \\
$\mathbf{5}$ & 1,164 & 6,469 & 57,757 & Venda de produtos \\
\hline \multicolumn{3}{c}{ Método de Extração: Alpha Factoring. }
\end{tabular}

Como se observa na Tabela 2, o primeiro fator agregou as assertivas 1, 3, 4, 5, 8 e 9. O segundo as de números 12, 13, 14 e 15. O terceiro fator as de números 6 e 10. As de números 2, 7, 17 e 18 compõem o quarto fator, e o quinto fator possui apenas a assertiva 16.

A Análise de Correspondência foi realizada com base na escala de Likert, construída para associar a percepção dos gestores (discordância/concordância) quanto ao processo orçamentário do banco. Para isso, os graus de discordância e concordância (discordo totalmente e discordo; concordo e concordo totalmente) da escala de Likert foram agrupados em apenas uma categoria (discordo e concordo). O produto final dessa análise é um mapa, denominado de Mapa de Percepção.

A análise do mapa de percepção geralmente se faz pelo exame das relações de proximidade geométrica (distâncias qui-quadrado) e por projeções em dimensões que podem ser identificadas a partir dos pontos do gráfico. Neste trabalho, o exame do mapa para identificar associações estatisticamente significantes (ao nível de 5\%) entre as variáveis (assertivas) e as categorias de resposta discordo/concordo (percepções dos gestores da instituição financeira) foi auxiliado com a realização de uma análise dos resíduos (PEREIRA, 2001). Os resultados desta análise permitiram diferenciar três grandes regiões de projeção para as dimensões de percepções dos gestores, como apresentado na Figura 1. 


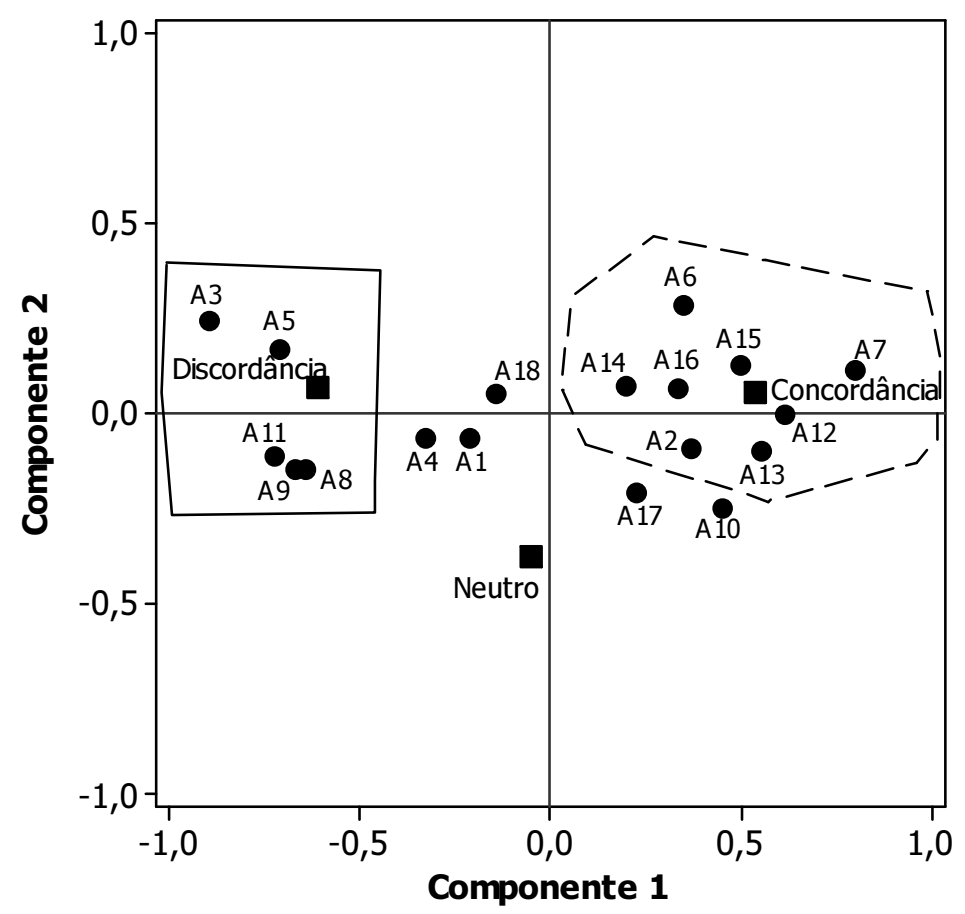

Figura 1: Mapa de percepção dos gestores quanto ao processo de orçamento da instituição.

De acordo com a Figura 1, as percepções de concordância dos gestores quanto ao processo orçamentário estão associadas às assertivas 2, 6, 7, 12, 13, 14, 15 e 16. Considerados os resultados da Análise Fatorial, identifica-se que essas assertivas estão alinhadas aos fatores 2 (cumprimento de metas), 3 (burocracia), 4 (hierarquia na tomada de decisões) e 5 (venda de produtos). As percepções de discordância dos gestores quanto ao processo orçamentário estão associadas às assertivas 3, 5, 8, e 9. Essas assertivas estão alinhadas ao fator 1 (eficiência na correção de erros) resultante da análise fatorial. É possível visualizar que algumas assertivas não estão associadas com as categorias de resposta discordo/concordo, o que indica uma indecisão dos gestores quanto à avaliação desses itens.

A Análise de Correspondência permitiu confirmar que as percepções quanto ao processo orçamentário são de que há discordância quanto àquelas assertivas relacionadas ao fator 1, e concordância quanto às assertivas relacionadas aos fatores 2, 3, 4 e 5 .

Finalmente, usou-se a Análise de Clusters, uma técnica multivariada de proximidade geométrica usada para detectar grupos homogêneos num conjunto de dados. O objetivo principal da Análise de Clusters é definir a estrutura dos dados colocando as observações mais parecidas em grupos, para que os objetos em cada cluster sejam semelhantes entre si e diferentes de objetos de outros clusters (HAIR JR. et al, 2008; PEREIRA, 2001).

O uso da Análise de Clusters permitiu associar as percepções dos gestores quanto ao processo orçamentário do banco a diferentes grupos de respondentes. Foi usado o Método de Ward (centróide) com a distância euclidiana quadrada como medida de similaridade entre os indivíduos (gestores). Segundo Hair Jr. et al (2008) e Pereira (2001) há três tipos de medidas de similaridade: de correlação, de distância e de associação, sendo que a distância euclidiana tem a vantagem de poder ser usada quando há variáveis quantitativas e/ou qualitativas 


\section{BEYOND BUDGETING - PERCEPÇÕES E ADAPTABILIDADE AO VAREJO BANCÁRIO: PESQUISA JUNTO AOS GESTORES DE UM GRANDE BANCO BRASILEIRO}

(medidas em termos nominal ou ordinal). Os resultados indicaram a formação de 2 grupos distintos de gestores.

Os 93 sujeitos pesquisados foram agrupados em dois clusters: o primeiro, com 51 e o segundo, com 41 respondentes. Para traçar o perfil dos clusters, foi usado o teste de Mann-Whitney (MW), para comparar as respostas dos clusters encontrados em cada assertiva mensurada. Quando a significância do teste foi maior que 0,05 , concluiu-se que os clusters possuíam a mesma opinião em relação à variável analisada (LEVIN e FOX, 2004; SIEGEL, 1981). A seguir, com base na frequência de concordâncias e discordâncias das questões, são descritas as características dos clusters.

O teste MW foi usado para verificar as variáveis discriminadoras, para as quais haveria diferença de opinião entre os clusters. O resultado do teste MW está nas colunas intermediárias da Tabela 2. A significância do teste MW apresentou valor menor que 0,05 para as assertivas 3, 4, 5, 8, 9, 13,14, 15 e 17, indicando opiniões distintas dos clusters nestas questões. Nas outras questões as opiniões dos clusters foram semelhantes. Os resultados da Análise de Clusters e do teste de Mann-Whitney estão na Tabela 2, juntamente com a descrição das assertivas, as cargas fatoriais e a composição dos fatores.

Para a melhor compreensão das diferenças de percepção entre os clusters, foram analisadas suas respostas por fator encontrado na Análise Fatorial. Nas últimas colunas da Tabela 2 estão as diferenças entre os clusters em relação a cada fator. Para facilitar a análise, as opções "concordo totalmente" e "concordo" foram agrupadas como "concordo" e as opções "discordo totalmente" e "discordo", como "discordo". Os resultados obtidos foram:

- Fator 1, percebeu-se que os sujeitos do cluster 1 tendem a discordar de todas assertivas, enquanto os do cluster 2 têm percepções mais divididas. Destacaram-se as assertivas 3 (os grupos pensam de forma semelhante) e 4 (pensam de forma totalmente contrária);

- Fator 2, os sujeitos do cluster 1 tendem a concordar com todas as assertivas. Os do cluster 2 apresentaram opiniões equilibradas entre concordância, discordância e indiferença em relação a esse grupo, com tendência a concordar nas assertivas 12 e 13, dividida quanto à assertiva 15 e contrária à visão do cluster 1 na questão 14

- Fator 3, constatou-se que os sujeitos dos clusters 1 e 2 pensam de forma semelhante;

- Fator 4, percebeu-se que os sujeitos dos clusters 1 e 2 possuíam opiniões semelhantes nas assertivas 2, 7 e 18, pois as diferenças entre os clusters não foram estatisticamente significantes. Sobre a centralização das decisões observou-se que a maioria dos integrantes do cluster 1 tendeu a afirmar que estas seriam centralizadas e que é comum submeter assuntos de pouca relevância às instâncias superiores (assertiva 17), enquanto o cluster 2 revelou-se dividido nesta questão. 
Tabela 2 - Matriz dos fatores rotacionada.

\begin{tabular}{|c|c|c|c|c|c|c|c|c|c|c|c|c|}
\hline \multirow{2}{*}{ Assertivas } & \multirow{2}{*}{$\begin{array}{c}\text { Carga } \\
\text { Fatorial }\end{array}$} & \multirow{2}{*}{$\begin{array}{c}\text { Alpha } \\
\text { Cronbach }\end{array}$} & \multirow{2}{*}{ Fatores } & \multicolumn{3}{|c|}{ Mann-Whitney } & \multicolumn{3}{|c|}{ Cluster 1} & \multicolumn{3}{|c|}{ Cluster 2} \\
\hline & & & & $\mathbf{U}$ & $\mathbf{Z}$ & Sig. & D & I & C & D & $I$ & $C$ \\
\hline $\begin{array}{l}\text { 5. Quando existe erro ou } \\
\text { desvio nos valores orçados, } \\
\text { as unidades afetadas } \\
\text { participam dos ajustes, } \\
\text { apoiadas por ferramentas } \\
\text { estatísticas eficientes. }\end{array}$ & ,677 & & & 612,000 & $\begin{array}{c}- \\
3,839\end{array}$ &, 000 & 49 & 1 & 1 & 21 & 7 & 14 \\
\hline $\begin{array}{l}\text { 4. O processo orçamentário } \\
\text { é eficiente e os valores } \\
\text { orçados sempre refletem o } \\
\text { que se espera } d a \\
\text { dependência em cada } \\
\text { período. }\end{array}$ & ,642 & & & 432,000 & $\begin{array}{c}- \\
5,326\end{array}$ &, 000 & 41 & 5 & 5 & 9 & 10 & 23 \\
\hline $\begin{array}{l}\text { 3. Eventuais erros ou } \\
\text { distorções nos valores } \\
\text { orçados são ajustados } \\
\text { imediatamente após sua } \\
\text { identificação. }\end{array}$ & ,509 & 0,729 & 1 & 752,500 & 2,792 &, 005 & 48 & 2 & 1 & 31 & 4 & 7 \\
\hline $\begin{array}{l}\text { 1. Os sistemas que apuram } \\
\text { custos, spreads e rateios } \\
\text { internos são eficientes, não } \\
\text { interferindo na gestão das } \\
\text { metas nas dependências. }\end{array}$ &, 502 & & & 888,000 & $\begin{array}{c}- \\
1,502\end{array}$ & ,133 & 29 & 7 & 15 & 16 & 8 & 18 \\
\hline $\begin{array}{l}\text { 9. A empresa é ágil na } \\
\text { análise dos resultados, } \\
\text { corrigindo imediatamente os } \\
\text { erros detectados. }\end{array}$ & 478 & & & 607,500 & $\begin{array}{c}- \\
3,988\end{array}$ & ,000 & 43 & 7 & 1 & 20 & 11 & 11 \\
\hline $\begin{array}{l}\text { 8. Os critérios utilizados } \\
\text { para corte de despesas são } \\
\text { justos e transparentes. }\end{array}$ & ,402 & & & 711,000 & $\begin{array}{c}- \\
3,080\end{array}$ & ,002 & 42 & 6 & 3 & 20 & 12 & 10 \\
\hline $\begin{array}{l}\text { 13. Parte dos gestores } \\
\text { cumpre metas a qualquer } \\
\text { custo, gerando retrabalho ou } \\
\text { perdas financeiras para a } \\
\text { empresa. }\end{array}$ & ,805 & & & 563,500 & ${ }^{-}, 218$ & ,000 & 1 & 4 & 46 & 11 & 11 & 20 \\
\hline $\begin{array}{l}\text { 15. Os gestores são levados } \\
\text { a desejar metas mais fáceis, } \\
\text { pois aos avaliadores } \\
\text { interessa o seu atingimento e } \\
\text { não o tamanho do desafio } \\
\text { vencido. }\end{array}$ & ,619 & 0,723 & 2 & 334,000 & $\begin{array}{c}- \\
6,126\end{array}$ & ,000 & 4 & 5 & 42 & 26 & 5 & 11 \\
\hline
\end{tabular}




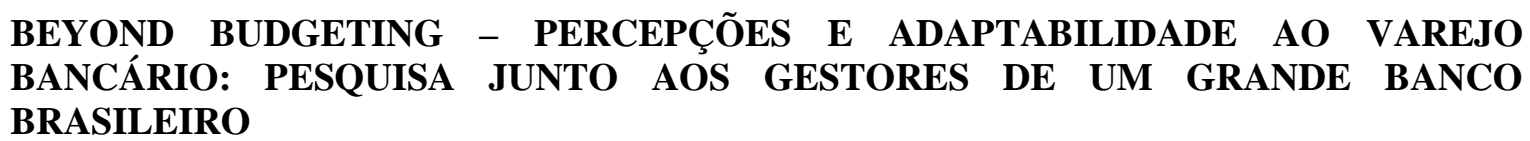

\begin{tabular}{|c|c|c|c|c|c|c|c|c|c|c|c|c|}
\hline $\begin{array}{l}\text { 14. Os administradores estão } \\
\text { mais interessados em obter } \\
\text { boas pontuações ou } \\
\text { classificações nos rankings } \\
\text { do que no efetivo } \\
\text { crescimento dos negócios e } \\
\text { cumprimento da estratégia } \\
\text { da empresa. }\end{array}$ & ,571 & $\mathbf{0 , 7 2 3}$ & 2 & 392,000 & $\begin{array}{c}- \\
5,559\end{array}$ & ,000 & 0 & 1 & 50 & 18 & 7 & 17 \\
\hline $\begin{array}{l}\text { 12. Às vezes são } \\
\text { reconhecidas pessoas que } \\
\text { apresentaram boa pontuação } \\
\text { nos sistemas de avaliação, } \\
\text { mas que não agregaram } \\
\text { valor de fato para o Banco. }\end{array}$ &, 484 & & & 772,500 & $\begin{array}{c}- \\
2,496\end{array}$ & ,013 & 5 & 2 & 44 & 6 & 10 & 26 \\
\hline $\begin{array}{l}\text { 10. O processo orçamentário } \\
\text { é lento, burocrático e com } \\
\text { alto consumo de estrutura. }\end{array}$ &, 813 & & & 766,000 & $\begin{array}{c}- \\
2,584\end{array}$ & , 010 & 7 & 5 & 39 & 7 & 15 & 20 \\
\hline $\begin{array}{l}\text { 6. O processo orçamentário } \\
\text { é muito detalhado e com } \\
\text { grande quantidade de itens, } \\
\text { dificultando o entendimento. }\end{array}$ & ,499 & 0,583 & 3 & 924,000 & $\begin{array}{c}- \\
1,230\end{array}$ & ,219 & 12 & 0 & 39 & 15 & 3 & 24 \\
\hline $\begin{array}{l}\text { 2. Existe apoio da alta } \\
\text { direção da empresa com } \\
\text { vistas à melhoria constante } \\
\text { do processo orçamentário. }\end{array}$ &, 585 & & & 848,000 & $\begin{array}{c}- \\
1,910\end{array}$ & ,056 & 13 & 10 & 28 & 7 & 5 & 30 \\
\hline $\begin{array}{l}\text { 18. Os órgãos superiores } \\
\text { dão apenas orientações e } \\
\text { direcionamentos } \\
\text { estratégicos, com pouca } \\
\text { interferência nos } \\
\text { microprocessos das } \\
\text { agências, permitindo total } \\
\text { autonomia do gerente em } \\
\text { sua agência. }\end{array}$ & ,477 & $\mathbf{0 , 5 7 8}$ & 4 & 996,000 & $\begin{array}{c}- \\
1,502\end{array}$ & ,539 & 23 & 5 & 23 & 21 & 6 & 15 \\
\hline $\begin{array}{l}\text { 17. As decisões na empresa } \\
\text { são centralizadas, sendo } \\
\text { comum submeter assuntos } \\
\text { de pouca relevância a } \\
\text { instâncias superiores. }\end{array}$ & ,464 & & & 824,000 & $\begin{array}{c}- \\
2,009\end{array}$ & ,045 & 8 & 11 & 32 & 16 & 8 & 18 \\
\hline $\begin{array}{l}\text { 7. Na elaboração dos } \\
\text { orçamentos há utilização } \\
\text { excessiva de série histórica, } \\
\text { levando a sempre exigir } \\
\text { mais de quem fez mais no } \\
\text { passado. }\end{array}$ & ,438 & & & $1,056,500$ &,- 123 & 902 & 3 & 3 & 45 & 2 & 5 & 35 \\
\hline $\begin{array}{l}\text { 16. É comum deixar para } \\
\text { gravar a venda de produtos } \\
\text { no momento em que for } \\
\text { mais conveniente. }\end{array}$ &, 515 & -- & 5 & 838,500 & $\begin{array}{c}- \\
1,916\end{array}$ & ,055 & 9 & 5 & 37 & 15 & 5 & 22 \\
\hline
\end{tabular}




\section{Cluster 1 - Visão Crítica}

Sobre o fator 1 (eficiência na correção de erros) pode-se dizer que os sujeitos tendem a concordar que o banco não é ágil na análise dos resultados, pois não corrige imediatamente os erros detectados (assertiva 9). Quando há erro ou desvio nos valores orçados as unidades afetadas não participam dos ajustes, apoiadas por ferramentas estatísticas eficientes (assertiva 5). Assim, eventuais erros ou distorções nos valores orçados não são ajustados logo após sua identificação (assertiva 3) e os critérios usados para corte de despesas não são justos e transparentes (assertiva 8). Além disso, os sistemas que apuram custos, spreads e rateios internos não são eficientes (assertiva 1). Neste sentido, afirmaram que o processo orçamentário não seria eficiente e os valores orçados não estariam refletindo o que se espera da dependência em cada período (assertiva 4).

Para o fator 2 (cumprimento de metas), os sujeitos tendem a afirmar que os gestores são levados a desejar metas mais fáceis, pois aos avaliadores interessa o seu alcance e não o tamanho do desafio vencido (assertiva 15). Assim, os gestores estariam mais interessados em boas pontuações ou classificações nos rankings do que no efetivo crescimento dos negócios e cumprimento da estratégia do banco (assertiva 14). Parte dos gestores cumpre metas a qualquer custo, gerando re-trabalho ou perdas financeiras (assertiva 13). Assim, às vezes estariam sendo reconhecidas pessoas com boa pontuação nos sistemas de avaliação, mas que não agregaram valor de fato para o banco (assertiva 12).

Quanto ao fator 3 (burocracia), tendem a afirmar que o processo orçamentário é lento, burocrático, com alto consumo de estrutura (assertiva 10), além de muito detalhado e com grande quantidade de itens, dificultando o entendimento (assertiva 6).

Para o fator 4 (hierarquia na tomada de decisão), tendem a concordar que apesar do apoio da alta direção para a melhoria constante do processo orçamentário (assertiva 2), as decisões são centralizadas, sendo comum submeter assuntos de pouca relevância a instâncias superiores (assertiva 17). Parte dos sujeitos tende a concordar que os órgãos superiores dão apenas orientações e direcionamentos estratégicos, com pouca interferência nos microprocessos das agências, permitindo total autonomia do gerente da agência (assertiva 18), enquanto outra parte tende a discordar. Assim, na elaboração dos orçamentos tendem a concordar que há uso excessivo de série histórica, levando a sempre exigir mais de quem fez mais no passado (assertiva 7).

Quanto ao fator 5 (venda de produtos), tendem a concordar que é comum deixar-se para gravar a venda de produtos no momento em que for mais conveniente (assertiva 16).

\section{Cluster 2 - Eficiência}

Para o fator 1 (Eficiência na correção de erros) verificou-se que os sujeitos tendem a afirmar que o processo orçamentário é eficiente e os valores orçados refletiriam o que se espera da dependência em cada período (assertiva 4). No entanto, admitem que o banco não é ágil na análise dos resultados, por não corrigir imediatamente os erros detectados (assertiva 9) e que, quando há erro ou desvio nos valores orçados, as unidades afetadas não participam dos 


\section{BEYOND BUDGETING - PERCEPÇÕES E ADAPTABILIDADE AO VAREJO BANCÁRIO: PESQUISA JUNTO AOS GESTORES DE UM GRANDE BANCO BRASILEIRO}

ajustes (assertiva 5). Assim, eventuais erros ou distorções nos valores orçados não são ajustados logo após sua identificação (assertiva 3) e os critérios usados para corte de despesas não são justos e transparentes (assertiva 8). Além disso, parte dos sujeitos tende a concordar que os sistemas que apuram custos, spreads e rateios internos não são eficientes (assertiva 1) e parte tende a discordar.

Sobre o fator 2 (cumprimento de metas), os sujeitos tendem a afirmar que os gestores não estão mais interessados em obter boas pontuações ou classificações nos rankings do que no efetivo crescimento dos negócios e cumprimento da estratégia do banco (assertiva 14), mas cumprem metas a qualquer custo, gerando re-trabalho ou perdas financeiras (assertiva 13). Assim, às vezes são reconhecidas pessoas que apresentaram boa pontuação nos sistemas de avaliação, mas que não agregaram valor de fato para o Banco (assertiva 12). Parte dos sujeitos tende a concordar que os gestores são levados a desejar metas mais fáceis, pois aos avaliadores interessa o seu alcance e não o tamanho do desafio vencido (assertiva 15), enquanto outra parte tende a discordar.

Quanto ao fator 3 (burocracia), tendem a afirmar que o processo orçamentário é lento, burocrático, com alto consumo de estrutura (assertiva 10), além de muito detalhado e com grande quantidade de itens, dificultando o entendimento (assertiva 6).

Para o fator 4 (hierarquia na tomada de decisão), os sujeitos tendem a concordar que há apoio da alta direção para a melhoria constante do processo orçamentário (assertiva 2), enquanto parte tende a concordar que as decisões são centralizadas, sendo comum se submeter assuntos de pouca relevância a instâncias superiores (assertiva 17) e outra parte tende a discordar. Parte dos sujeitos tende a concordar que os órgãos superiores dão apenas orientações e direcionamentos estratégicos, com pouca interferência nos microprocessos das agências, permitindo total autonomia do gerente da agência (assertiva 18), enquanto outra parte tende a discordar. Assim, na elaboração dos orçamentos tendem a concordar que há utilização excessiva de série histórica, levando a sempre exigir mais de quem fez mais no passado (assertiva 7).

Sobre o fator 5 (venda de produtos), tendem a concordar que é comum deixar-se para gravar a venda de produtos no momento em que for mais conveniente (assertiva 16).

Pode-se concluir que os sujeitos do cluster 1 acreditam que o processo orçamentário não é eficiente e nem ágil na correção dos erros, enquanto os do cluster 2 consideram este processo eficiente, mas não ágil. Conclui-se, ainda, que os integrantes do cluster 1 afirmam que os administradores estão interessados em boas pontuações e que, talvez por isso, cumprem metas a qualquer custo. O cluster 2 acredita que os administradores estão mais interessados na estratégia da empresa, mas também cumprem metas a qualquer custo.

Foi constatado que os clusters não apresentaram diferenças com relação à suas respostas nas oito questões que descrevem o perfil dos respondentes no instrumento de pesquisa. É o que se apresenta a seguir. 


\subsection{Perfil dos Clusters e as Categorias dos Respondentes}

O perfil dos dois clusters encontrados foi analisado com base em suas respostas às questões categóricas. Para isso, usou-se o teste do Qui-quadrado, pois as questões foram mensuradas ao nível nominal. O teste buscou detectar se havia diferenças em relação ao nível hierárquico, formação, idade ou experiência dos respondentes. Na Tabela 3, a seguir, são apresentados os valores das correlações para estas questões, na coluna Valor-p.

Tabela 3 - Correlação entre os clusters e as variáveis categóricas.

\begin{tabular}{l|r|r|r}
\hline \multicolumn{1}{c|}{ Questões } & \multicolumn{1}{c|}{$\chi^{2}$} & $\begin{array}{r}\text { Graus de } \\
\text { liberdade }\end{array}$ & Valor-p \\
\hline Nível hierárquico do cargo ocupado & 2,679 & 2 &, 262 \\
Grau de instrução &, 274 & 1 &, 601 \\
Formação Superior & 4,792 & 4 &, 309 \\
Gênero &, 977 & 1 &, 323 \\
Região onde trabalhou por mais tempo na carreira & 3,880 & 2 &, 144 \\
Como você considera sua agência (ou Região, se não for Gerente)? &, 861 & 2 &, 650 \\
Há quantos anos você atua como Administrador? & 4,788 & 4 &, 310 \\
Faixa etária do respondente & 1,822 & 3 &, 610 \\
\hline
\end{tabular}

A Tabela 3 revela que a significância do teste do Qui-quadrado apresentou valor maior que 0,05 para todas as variáveis, indicando que os clusters não diferem a respeito destas questões. Assim, não foi possível afirmar que determinada categoria se enquadre em um ou outro cluster, devido ao valor apurado para o Qui-quadrado.

\section{CONSIDERAÇÕES FINAIS}

Este trabalho pretendeu estudar questões ligadas ao processo orçamentário em um banco de grande porte, que atua no varejo bancário brasileiro. A pesquisa buscou detectar problemas com o processo orçamentário que apontassem para a aplicabilidade do modelo Beyond Budgeting. Extraiu-se do referencial teórico um conjunto de problemas e comportamentos que foram investigados na pesquisa, com a aplicação de um questionário a um grupo de gestores da instituição.

A análise do modelo usado pelo banco revelou uma relação direta dos orçamentos com metas fixas e sistemas de avaliação e reconhecimento. A análise das respostas obtidas permitiu detectar a percepção do grupo de gestores pesquisado, sobre os problemas previstos pelos defensores do Beyond Budgeting.

A Análise Fatorial revelou cinco fatores, e os dois primeiros responderam por 36,3\% da variância. A análise dos cinco fatores: "Eficiência na correção de erros", "Cumprimento de Metas", "Burocracia", "Hierarquia na tomada de decisões" e "Vendas de produtos", indicou como as assertivas se relacionaram dentro de cada fator.

A Análise de Correspondência permitiu confirmar que as percepções quanto ao processo orçamentário são de que há discordância quanto àquelas assertivas relacionadas ao fator 1, e concordância quanto às assertivas relacionadas aos fatores 2, 3, 4 e 5 . 


\section{BEYOND BUDGETING - PERCEPÇÕES E ADAPTABILIDADE AO VAREJO BANCÁRIO: PESQUISA JUNTO AOS GESTORES DE UM GRANDE BANCO BRASILEIRO}

A Análise de Correspondência permitiu corroborar os resultados obtidos pela Análise Fatorial. As assertivas associadas às percepções de concordância e discordância, em geral, permitiram discriminar os gerentes em grupos nos fatores obtidos pela análise fatorial (ver Tabela 2).

Na Análise de Clusters, foram definidos dois grupos de respondentes, um com 51 e outro com 41 respondentes. $\mathrm{O} 1^{\circ}$ grupo apontou erros e desvios no sistema atual, entendendoo como ineficiente e pouco ágil, permitindo maior valorização do jogo empresarial do que o comprometimento com a estratégia empresarial, fato apontado por Frezatti (2004). No $2^{\circ}$, os sujeitos acreditaram que o processo orçamentário atual é eficiente, percebendo os gestores comprometidos com as estratégias. Porém, apontaram pouca agilidade e a demora na resolução dos problemas, mesmo depois de detectados, o que pode acarretar duas visões distintas, fato a ser investigado no futuro. Apontaram também uma incoerência, pois não é possível que os sistemas sempre reflitam o que se espera de uma dependência, se não houver agilidade nas correções. Revelaram acreditar que, mesmo sem a agilidade desejada, os gestores sabem o que deles é esperado, permitindo um sistema eficiente.

Os dois grupos concordaram que, mesmo com o apoio da cúpula ao desenvolvimento do sistema de gestão: a) buscam-se metas a qualquer custo, sem a percepção da agregação de valor; b) as pessoas são reconhecidas por pontuações, e não pelo valor agregado; c) o processo orçamentário é lento, burocrático e detalhado; d) a estrutura atual não favorece a cooperação entre agências; e) o uso da série histórica é excessivo. A possibilidade de tais ocorrências foi apontada por autores nacionais e internacionais (FREZATTI, 2004; DAUM et al, 2005; WAAL, 2005; SHASTRI, STOUT, 2008).

Ao considerar a concordância nos itens acima citados, a existência de uma relativa maioria no grupo com a visão mais crítica ao sistema atual (51 sujeitos) e que o grupo menor é indeciso em questões importantes, como centralização, microgestão e autonomia, pode-se inferir a necessidade de mudanças no atual sistema de gestão, na forma proposta pelos defensores do Beyond Budgeting (BBRT, 2006).

A resposta ao problema de pesquisa, portanto, é: sim, pelas respostas do grupo respondente da pesquisa, pode-se dizer que as evidências são suficientes para motivar a adoção de um novo modelo de gestão. Agilidade, autonomia e agregação de valor são fatores críticos de sucesso para qualquer ramo de atividade na economia moderna. Um sistema com as características defendidas pelo BBRT (2006) poderia ser uma alternativa para a manutenção da competitividade da empresa.

O modelo Beyond Budgeting poderia resolver alguns problemas detectados: a) a eliminação do orçamento e comparação com metas fixas, apoiado por ferramentas adequadas, poderia inibir atitudes que não agregam valor à empresa; b) os princípios de gestão defendidos, apoiados por ferramentas adequadas, permitiriam tomar decisões que trouxessem ganhos aos acionistas e melhorassem os processos, mantendo a atratividade do banco, sua competitividade e a capacidade de concentrar seus processos onde há percepção de valor a ser compartilhado com os clientes; c) a autodeterminação de metas poderia trazer maior comprometimento, e a comparação com benchmarks móveis deveria levar a uma competição 
saudável, trazendo dinamismo à gestão; d) o uso de ferramentas como, por exemplo, Rolling Financial Forecasting, Rolling Investment Management e Benchmarks, em vez do orçamento estático (DAUM et al, 2005, p. 65), com melhoria no sistema de informação gerencial, poderia eliminar procedimentos burocráticos, desperdícios de tempo e mão-de-obra com discussões sobre o processo orçamentário. $\mathrm{O}$ banco poderia olhar sempre para frente, em vez de esperar dias para saber como fechou o mês anterior.

A competição no mercado financeiro brasileiro será cada dia mais forte e, certamente sobreviverão os bancos mais competentes. Pode-se concluir que, na visão do grupo pesquisado, o Beyond Budgeting é aplicável ao banco objeto da pesquisa, podendo ser capaz de torná-lo mais dinâmico, com alta performance, independentemente desses desafios e transformações.

Certamente há outras formas de se promover uma mudança, o que pode ocorrer gradativamente ou de forma acelerada. Estudos futuros poderão complementar esse processo de transição, auxiliando o nível estratégico do banco a tomar as melhores decisões, dentre os quais investigando se a adoção do Balanced Scorecard, combinada com outros instrumentos de gestão, vem contribuindo para melhorar a eficácia empresarial de organizações onde tal fato ocorre, dentre as quais o banco aqui estudado.

\section{REFERÊNCIAS}

BARBOSA FILHO, F.; PARISI, C.. Análise da aderência ao modelo Beyond Budgeting Round Table: O Caso Sadia S/A. Revista Universo Contábil, V. 2, n. 1, p. 26-42, jan/abr 2006. Disponível em: <http://proxy.furb.br/ojs/index.php/universocontabil/article/view/105/64>. Acesso em: 16 nov. 2011.

BBRT. Beyond Budgeting Round Table. [2006]. Disponível em: 〈http://www.bbrt.org>. Acesso em: 16 jun. 2006.

BRASIL. Banco Central. Comunicado BACEN 14.259, de 9 de março de 2006. Comunica procedimentos para convergência das normas de contabilidade (...) com as normas do IASB. Brasília (DF), 9 mar. 2006

BROOKSON, Stephen. Como elaborar orçamentos. 2. ed. São Paulo: Publifolha, 2000.

COLLIS, J.; HUSSEY, R. Pesquisa em Administração: um guia prático para alunos de graduação e pós-graduação. 2. ed. Porto Alegre: Bookman, 2005.

COOPER, D. R.; SCHINDLER, P. S. Métodos de pesquisa em administração. 7. ed. Porto Alegre: Bookman, 2003.

DAUM, J. H.; GUNZ, R.; LUTHI, J. D.; MORLIDGE, S. Beyond Budgeting - breaking free from the annual fixed budget: a discussion between experts from Borealis, Nestlé, Unilever and SAP. Measunring Business Excellence. Vol, 9, N. 1, 2005, p. 64-70. Disponível em: $<$ http://search.proquest.com/business/docview/208749754/1337E28F5957247671/1?accounti $\underline{\mathrm{d}=34586}$ > . Acesso em: 16 nov. 2011. 
FLEURY, M. T. L.; SHINYASHIKI, G. T.; STEVANATO, L. A. Arqueologia teórica e dilemas metodológicos dos estudos sobre cultura organizacional. In: MOTTA, F. C. P.; CALDAS, M. P. Cultura organizacional e cultura brasileira. São Paulo: Atlas, 1997.

FREZATTI, F. Além do orçamento: existiria alguma chance de melhoria do gerenciamento? Brazilian Business Review. Vitória, v.1, n.2, 2004. p.122-140.

HAIR JR., J. F. et al. Análise multivariada de dados. 5. ed.Porto Alegre: Bookman, 2008.

HARMAN, H. H. Modern factor analysis. Chicago: The University of Chicago Press, 1976.

HOPE, J.; FRASER, R. Beyond budgeting: how managers can break free from the annual performance trap. Massachusetts: Harvard, 2003.

; _ Beyond budgeting questions and answers, Oct. 2001. Disponível em:

<http://www.beyondbudgeting.com.br/pdf/Paper_Q\&A.pdf>. Acesso em: 14 jul. 2006.

; __ Quem precisa de orçamentos? Harvard Business Review América Latina,

Santiago, v. 81, n. 2, p. 1-9, fev. 2003b.

HORNGREN, C. T.; FOSTER, G.; DATAR, S. M. Cost accounting: a managerial emphasis. 9. ed. New Jersey: Prentice Hall, 1997.

JENSEN, M. C. Paying people to lie: the truth about the budgeting process. (Harvard Business School Working Paper; 01-072). Sept .2001. Disponível em: <http://papers.ssrn.com/paper=267651>. Acesso em: 20 out. 2006.

KOOGAN, A.; HOUAISS, A. (coord.). Enciclopédia e dicionário ilustrado. Rio de Janeiro: Delta, 1998.

LEE, T. W. Using qualitative methods in organizational research. Thousand Oaks: Sage, 1999.

LEVIN, J.; FOX, J. C. Estatística aplicada às ciências humanas. São Paulo: Pearson Education, 2004.

LINDSAY, M.; LIBBY, T. Svenska Handelsbanken: controlling a redically descentralized organization without budgets. Issues in Accounting Education. Vol. 22, N. 4, November 2007, p. 625-640. Disponível em: http://search.proquest.com/business/docview/210884019/1337E2AF5AD7A5DE918/1 ?accou ntid=34586. Acesso em: 16 nov. 2011.

LUNKES, R. J. Contribuição à melhoria do processo orçamentário empresarial. 2003. Tese (Doutorado em Engenharia de Produção) - Universidade Federal de Santa Catarina, Florianópolis, 2003. Disponível em: <http://www.teses.usp.br/teses/disponiveis/12/12136/tde15052002-094025/publico/TDE.pdf >. Acesso em: 18 set. 2006.

MALHOTRA, N. K. Pesquisa de marketing: uma orientação aplicada. 3. ed. Porto Alegre: Bookman, 2001. 
MAX, M. Beyond Budgeting: case studies in north american financial services. Journal of Performance Management, Mar2005, Vol. 18 Issue 1, p3-15, 13 p.

OLIVEIRA, T. M. V. Escalas de mensuração de atitudes: Thurstone, Osgood, Stapel, Likert, Guttman, Alpert. Revista Brasileira de Gestão e Negócios (RBGN), Vol. 2, N. 2, 2001.

PASQUALI, L. Psicometria: teoria dos testes na psicologia e na educação. Petrópolis: Vozes, 2003.

PELEIAS, I. R. Controladoria: gestão eficaz utilizando padrões. São Paulo: Saraiva, 2002.

PEREIRA, J. C. R. Análise de dados qualitativos: estratégias metodológicas para as ciências da saúde, humanas e sociais. São Paulo: EDUSP, 2001.

PESTANA, M. H.; GAGEIRO, J. N. Análise de dados para ciências sociais: a complementaridade do SPSS. 2. ed. Lisboa: Edições Silabo, 2000.

PFLAEGING, N. 11 pecados capitais na implementação e uso do Balanced Scorecard: como criar organizações verdadeiramente flexíveis e descentralizadas, baseadas nos princípios do Beyond Budgeting. Palestra. Associação Nacional dos Executivos de Finanças e Contabilidade - ANEFAC. São Paulo, jun. 2005.

RACHLIN, R. (org.). Handbook of budgeting. $4^{\text {th }}$ ed. New York: Wiley, 1999.

SHASTRI, K.; STOUT, D, E, Budgeting: perspectives from the real world. Management Accounting Quarterly, Fall, 2008, Vol. 10, N. 1. p. 18-25. Disponível em: http://search.proquest.com/business/docview/222802149/1337E2C360C444C8042/1?accounti $\underline{\mathrm{d}=34586}$ > . Acesso em: 16 nov. 2011.

SIEGEL, S. Estatística não-paramétrica. São Paulo: McGraw-Hill do Brasil, 1981.

SILVA, D.; SIMON, F. O. Abordagem quantitativa de análise de dados de pesquisa: construção e validação de escala de atitude. Cadernos do CERU, Série 2, N. 16, p. 11-27, 2005 .

SPSS. Statistical package for the social sciences: base 10.0 user's guide. Chicago: SPSS, 1999.

WAAL, A. A. Insights from practice: is your organizations ready for beyond buedgeting ? Measuring Business Excellence. Vol. 9, N. 2, 2005, p. 56-67. Disponível em: http://search.proquest.com/business/docview/208748235/1337E2D75B656BA7AAE/10?acco untid=34586 $>$. Acesso em: 16 nov. 2011.

WELSCH, G. A. Orçamento empresarial. 4. ed. São Paulo: Atlas, 1983. 